\title{
Using Rational Polynomial Functions for rectification of GeoEye-1 imagery
}

\author{
Pasquale Maglione, Claudio Parente, Andrea Vallario \\ (Department of Sciences and Technologies, University of Naples "Parthenope", Italy)
}

\begin{abstract}
GeoEye-1 panchromatic images (geometric resolution: $0.5 \mathrm{~m}$ ) can be rectified using Rational Polynomial Functions (RPFs) without knowledge of the full sensor information: rectification is conducted using DEM (Digital Elevation Model) of the area as well as Ground Control Points (GCPs) of which both elevation and $X, Y$ position must be known. Check Points (CPs) with the same characteristics of GCPs (but not coincident with them) are used to verify the accuracy of the product. For both GCPs and CPs coordinates can be not only obtained with survey, but also derived from detailed maps or orthophotos (scale 1:5,000 or greater). In this paper methods to rectify GeoEye-1 images using orthophotos (scale 1:2,000) for GCPs and CPs detection are considered, with particular attention to achieved positional accuracy. The research is performed on GeoEye-1 panchromatic image of an area in Campania region (Italy) around the mouth of Volturno river and Domitian coast: differences between the coordinates of GCPs (as well as of the Check Points) on the ortophotos and the corresponding values on the rectified image are calculated and analyzed to define quality of resulting product. The variability of results in relation to the number of GCPs is analysed, also considering possibilities to use additional information that is usually supplied by providers with Rational Polynomial Coefficients (RPCs).
\end{abstract}

Keywords: GeoEye-1 imagery, rectification, RPFs, RPCs, GCPs, CPs

\section{INTRODUCTION}

On board of GeoEye-1 satellite two types of sensors are operative: the first collects panchromatic images $(0.450 \mu \mathrm{m}-0.800 \mu \mathrm{m})$ with 0.41 meter resolution at nadir, the second multispectral imagery (Blue: $0.450 \mu \mathrm{m}-0.510 \mu \mathrm{m}$; Green: $0.510 \mu \mathrm{m}-0.580 \mu \mathrm{m}$; Red: $0.655 \mu \mathrm{m}-0.690 \mu \mathrm{m}$; Near-Infrared: $0.780 \mu \mathrm{m}-$ 0.920 ) with 1.65 meter resolution at nadir [1]. For commercial uses panchromatic images are down-sampled to $0.5 \mathrm{~m}$, multispectral ones to $2 \mathrm{~m}$. Specifications for GeoEye-1 estimate an accuracy in planimetric location of better than $3 \mathrm{~m}$ without ground control, specifically $2.5 \mathrm{~m}$ Circular Error 90\% (CE90=Radial error distance centered at zero within which $90 \%$ of the data points fall) [2].

GeoEye-1 images, if geometrically corrected and georeferenced, supply detailed information about morphological configurations, situations of natural and urban environments, state of agricultural cultivations and forests, and so on. They will thus constitute a suitable source of imagery for large scale topographic mapping, to scales of 1:5,000 and possibly larger [3].

\section{METHODS TO RECTIFY HIGH RESOLUTION SATELLITE IMAGES}

To rectify high resolution satellite images two different approaches can be adopted: the first is based on rigorous models that apply collinear equations to pushbroom acquisition technique; the second is based on nonparametric models that are independent of the acquisition method as well as of the sensor characteristics. In the first case orientation parameters are modelled as time dependent polynomials of second order or higher: approximated initial values are necessary to estimate the unknowns and they can be extracted from the metadata files that are supplied with the images [4].

Within the second group, Rational Function Model (RFM) is one of the most used [5]. It defines relationship between images coordinates (i,j) and 3D object coordinates (X,Y,Z) using 3D Rational Polynomial Functions (RPFs):

$$
\begin{gathered}
i=\frac{P_{1}(X, Y, Z)}{P_{2}(X, Y, Z)} \\
j=\frac{P_{3}(X, Y, Z)}{P_{4}(X, Y, Z)}
\end{gathered}
$$
coefficients)

where $\mathrm{P}_{1}, \mathrm{P}_{2}, \mathrm{P}_{3}$ and $\mathrm{P}_{4}$ are usually maximum degree polynomials equal to 3 (corresponding to 20 
For example, polynomial $\mathrm{P}_{1}$ is:

$$
\begin{aligned}
& a_{000}+a_{100} X+a_{010} Y+a_{001} Z+a_{110} X Y+a_{101} X Z+a_{011} Y Z+a_{200} X^{2}+a_{020} Y^{2}+a_{002} Z^{2}+a_{111} X Y Z+ \\
& a_{210} X^{2} Y+a_{201} X^{2} Z+a_{120} Y^{2} X+a_{021} Y^{2} Z+a_{102} Z^{2} X+a_{012} Z^{2} Y+a_{300} X^{3}+a_{030} Y^{3}+a_{003} Z^{3}
\end{aligned}
$$

For consequence a generic polynomial can be expressed as:

$$
P_{n}(X, Y, Z)=\sum_{i=0}^{m_{1}} \sum_{j=0}^{m_{2}} \sum_{k=0}^{m_{3}} a_{i j k} X^{i} Y^{j} Z^{k}
$$

where:

$$
\begin{aligned}
& 0 \leq m_{1} \leq 3 ; \\
& 0 \leq m_{2} \leq 3 ; \\
& 0 \leq m_{3} \leq 3 ; \\
& m_{1}+m_{2}+m_{3} \leq 3
\end{aligned}
$$

To determine values of the coefficients, Ground Control Points (GCPs), of which both i,j and XYZ coordinates are known, must be considered. In the polynomials $\mathrm{P}_{2}$ and $\mathrm{P}_{4}$ the first terms are assumed equal to 1 , so 78 coefficients are present in (1) and (2). For consequence at least 39 GCPs are necessary. Accuracy of solution depends from the number and the distribution of GCPs. Best results, in fact, are obtained using a large number of GCPs which must have also a regular distribution both planimetric and altimetric. To estimate accuracy of results it is necessary to consider errors in the reference points that are not only GCPs but also Check Points (CPs): for them i,j and XYZ coordinates must be known [6] [7] [8]. The application of RPFs requires also the availability of DEM (Digital Elevation Model) of the whole area.

The coefficients of the polynomials are often supplied with the image (Rational Polynomial Coefficients, RPCs): they are generated by the image provider considering the position of the satellite at the time of image capture [9]. Software for rectification generally permit the user to introduce GCPs to improve coefficients calculation, but in this case high quality of results is achieved with a smaller number of Points.

\section{APPLICATION OF RPFS TO GEOEYE-1 IMAGE}

GeoEye-1 panchromatic image concerning an area in Campania region (Italy) around the mouth of Volturno river and Domitian coast is considered to compare different approaches for rectification (Fig. 1).

The zone is particularly interesting for environmental as well as anthropic aspects: in the last decades the shoreline has been interested by intensive erosion as well as sediments accumulation [10]; it includes the Regional Natural Reserve Volturno River - Coast of Licola that protects a mosaic of natural environments (with dune ridges colonized by mastic, heather, juniper, rosemary, buckthorn and arbutus) survived to the urbanization of the coastline [11]. For those and more other elements the whole zone requires continuous monitoring actions that can be based also on satellite images to which high values of spatial resolution and positional accuracy are required.

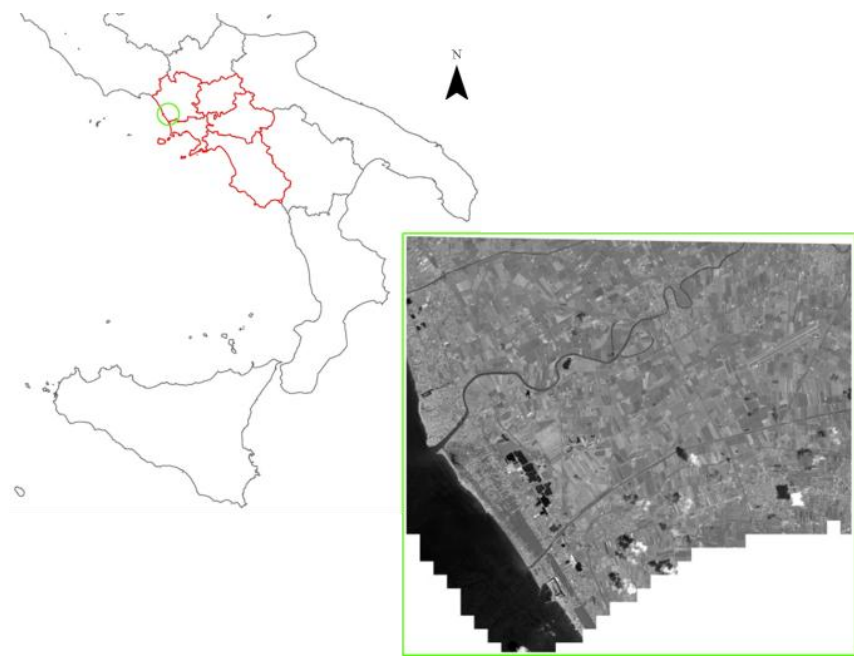

Fig. 1 - The considered GeoEye-1 scene (area around the mouth of Volturno river and Domitian coast) and its location in Campania region (Italy) 
The considered GeoEye-1 is accompanied by RPCs generated by the provider. Rectification processes are conducted using PCI Geomatica OrthoEngine in two different ways, with and without original RPCs. GCPs and CPs planimetric coordinates are derived from orthophotos of Campania Region at scale 1:2,000, while elevations are obtained by DEM of the area with grid $2 \mathrm{~m} \times 2 \mathrm{~m}$.

In Tables 1 and 2 statistic values (maximum, minimum, mean, standard deviation, RMS) of the residual errors obtained for GCPs and CPs in XY direction are reported, in reference to different possibilities for RFM application. Particularly, the following options are considered: RPCs use with 0, 5, 10, 15 GCPs (Fig. 2, 3, 4, 5); RPFs use (without RPCs of the provider) with 45, 60 and 90 GCPs (Fig. 6, 7, 8); for all situations the same 15 CPs are introduced. Increasing number of GCPs provides more accurate results both with or without RPCs: in the first case, few points are necessary to achieve elevate levels of accuracy; on the other site, without RPCs several GCPs must be used. Residual errors testify that rectified image obtained from application of RPFs with RPCs and 15 GCPs presents high accuracy, so to be used as product at scale 1:5,000 or greater.

Table 1 - Residuals (in meters) obtained for Ground Control Points and Check Points by using RPCs

\begin{tabular}{|c|c|c|c|c|c|}
\hline RPCs & $\begin{array}{c}\text { Mean } \\
(\mathrm{m})\end{array}$ & $\begin{array}{c}\text { Min } \\
(\mathrm{m})\end{array}$ & $\begin{array}{c}\text { Max } \\
(\mathrm{m})\end{array}$ & $\begin{array}{c}\text { St. dev. } \\
(\mathrm{m})\end{array}$ & $\begin{array}{c}R M S \\
(\mathrm{~m})\end{array}$ \\
\hline CPs: 15 & 2.646 & 1.286 & 3.749 & 0.649 & 2.724 \\
\hline GCPs: 5 & 0.716 & 0.492 & 0.950 & 0.152 & 0.732 \\
\hline CPs: 15 & 1.230 & 0.158 & 2.838 & 0.718 & 1.424 \\
\hline GCPs: 10 & 0.494 & 0.095 & 1.006 & 0.287 & 0.571 \\
\hline CPs: 15 & 1.013 & 0.160 & 2.459 & 0.688 & 1.225 \\
\hline GCPs: 15 & 0.643 & 0.276 & 1.355 & 0.321 & 0.719 \\
\hline CPs: 15 & 1.014 & 0.124 & 2.603 & 0.710 & 1.237 \\
\hline
\end{tabular}

Table 2 - Residuals (in meters) obtained for Ground Control Points and Check Points by using RPFs without RPCs

\begin{tabular}{|c|c|c|c|c|c|}
\hline No RPCs & $\begin{array}{c}\text { Mean } \\
(\mathrm{m})\end{array}$ & $\begin{array}{c}\text { Min } \\
(\mathrm{m})\end{array}$ & $\begin{array}{c}\text { Max } \\
(\mathrm{m})\end{array}$ & $\begin{array}{c}\text { St. dev. } \\
(\mathrm{m})\end{array}$ & $\begin{array}{c}\text { RMS } \\
(\mathrm{m})\end{array}$ \\
\hline GCPs: 45 & 0.454 & 0.015 & 1.329 & 0.343 & 0.570 \\
\hline CPs: 15 & 1.625 & 0.355 & 4.444 & 1.033 & 1.925 \\
\hline GCPs: 60 & 0.619 & 0.074 & 1.698 & 0.382 & 0.728 \\
\hline CPs: 15 & 1.309 & 0.315 & 1.964 & 0.489 & 1.397 \\
\hline GCPs: 90 & 0.821 & 0.055 & 1.867 & 0.454 & 0.938 \\
\hline CPs: 15 & 1.154 & 0.178 & 1.944 & 0.511 & 1.262 \\
\hline
\end{tabular}

\section{CONCLUSION}

Using Rational Polynomial Functions rectification of high resolution images such as GeoEye-1 can be conducted without knowledge of acquisition method as well as of the sensor characteristics. The test presented in this paper for GeoEye-1 image confirms that high accuracy can be obtained using detailed orthophotos to derive coordinates of GCPs. In this case, even if accuracy levels which are guaranteed with survey (for example with the use of GNSS geodetic receivers) can't be achieved, interesting results are obtained if the scale of orthophotos is great. Application of RPFs with RPCs permits to use smaller number of GCPs. The low cost and availability of GeoEye-1 base products encourages to apply RFM, so to obtain, with contained consumption of resources, ortho products for several applications, such as maps updating. The best results of this case study confirm possibility to use GeoEye-1 images for 1:5,000 scale topographic mapping. 


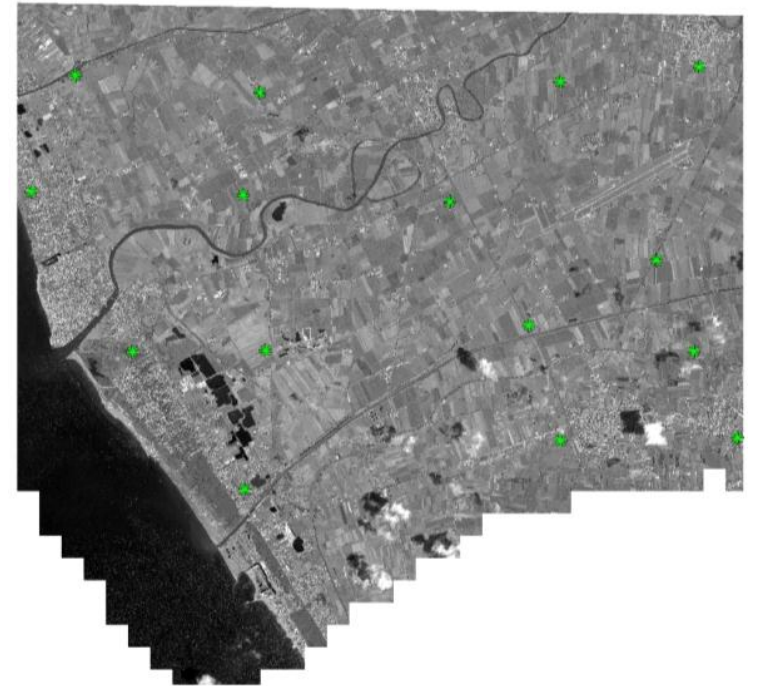

Fig. 2 - Rectification with RPCs and 15 CPs (in green)

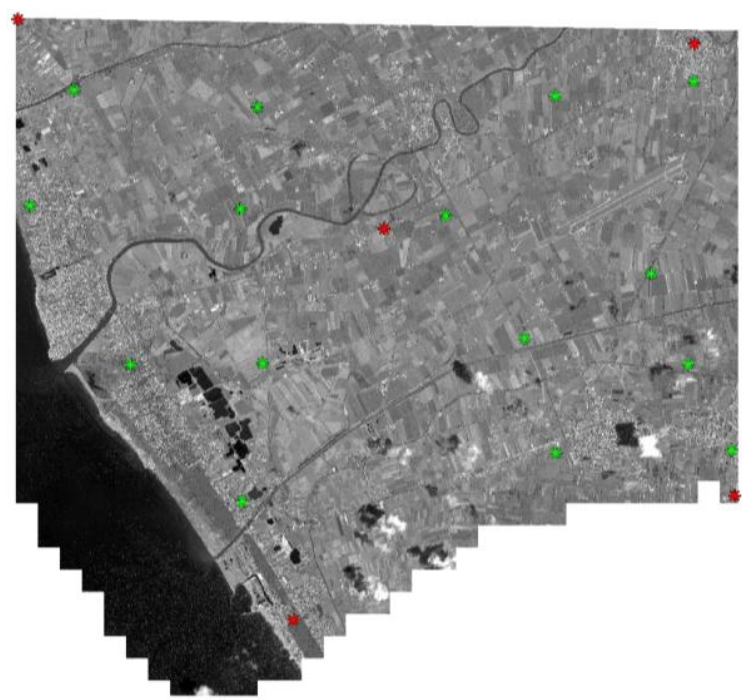

Fig. 3 - Rectification with RPCs, 5 GCPs (in red) and 15 CPs (in green)

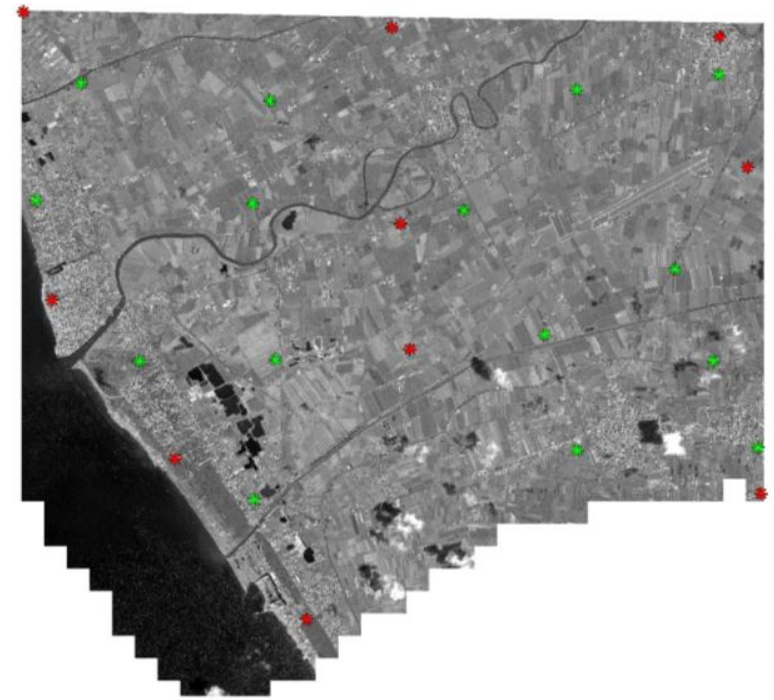

Fig. 4 - Rectification with RPCs, 10 GCPs (in red) and 15 CPs (in green) 


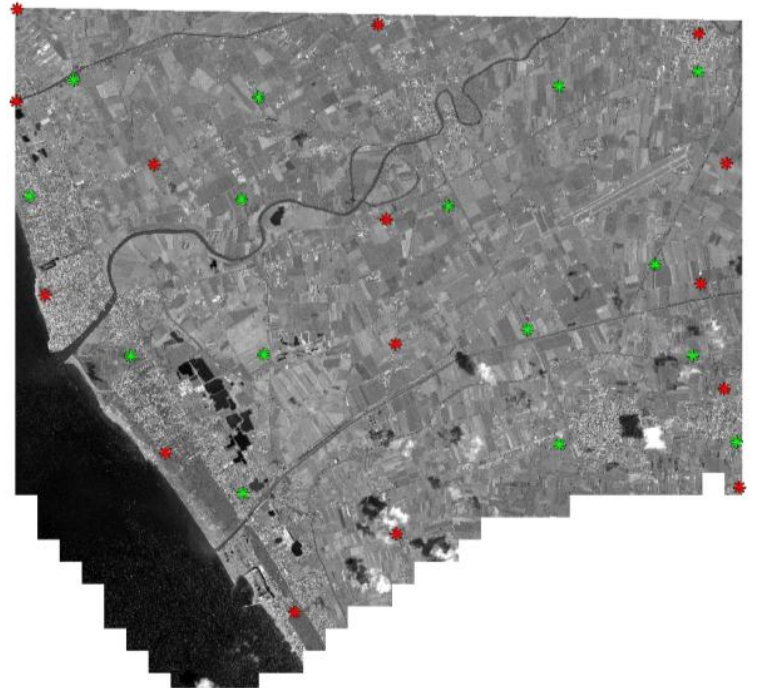

Fig. 5 - Rectification with RPCs, 15 GCPs (in red) and 15 CPs (in green)

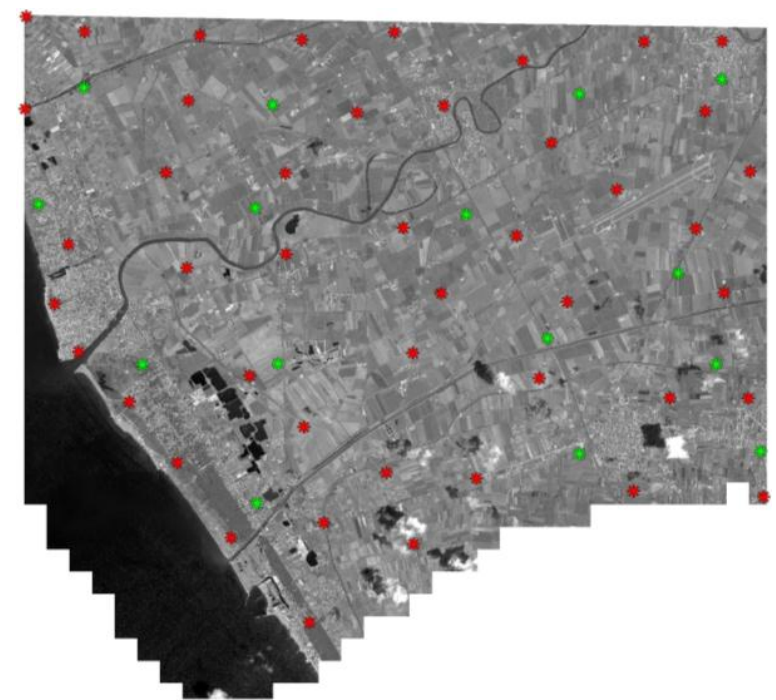

Fig. 6 - Rectification without RPCs and with 45 GCPs (in red) and 15 CPs (in green)

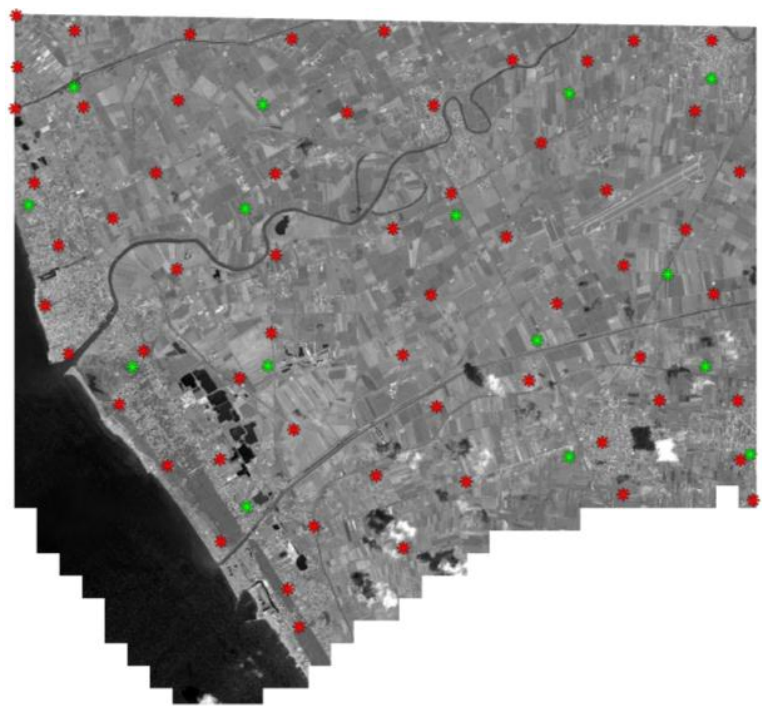

Fig. 7 - Rectification without RPCs and with 60 GCPs (in red) and 15 CPs (in green) 


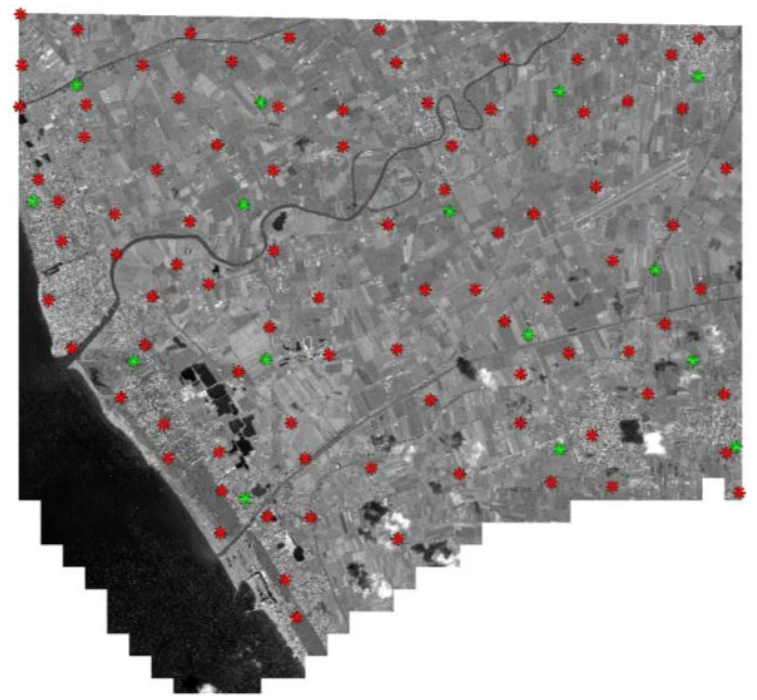

Fig. 8 - Rectification without RPCs and with 90 GCPs (in red) and 15 CPs (in green)

\section{REFERENCES}

[1] Satellite Imaging Corporation, GEOEYE-1 Satellite Sensor, 2013. http://www.satimagingcorp.com/satellite-sensors/geoeye-1.html. Last access: 01/09/2013.

[2] GeoEye-1, Fact Sheet, GeoEye-1: the world's highest resolution commercial earth-imaging satellite. http://launch.geoeye.com/LaunchSite/assets/documents/geoeye1_factsheet_v8.pdf. Last access: 12/05/2013).

[3] S. Clive Fraser and M. Ravanbakhsh, Georeferencing Accuracy of GeoEye-1 Imagery, Photogrammetric Engineering \& Remote Sensing, 75(6), 2009, $634-638$.

[4] T. Toutin, R. Chenier and Y. Carbonneau, 3D geometric modelling of Ikonos Geo images, Proc. Joint ISPRS Workshop High Resolution Mapping from Space 2001, Hannover, 2001. (on CD ROM).

[5] C. V. Tao and Y. Hu, Image rectification using a generic sensor model - Rational Function Model, International Archives of Photogrammetry and Remote Sensing, Vol. XXXIII, Part B3, 2000, 874-881.

[6] E.P. Baltsavias, Geometric transformations and registration of images, orthoimage generation and mosaicking, Institute of Geodesy and Photogrammetry, ETHZ Zurich, 2000.

[7] F. Guastaferro, P. Maglione and C. Parente, Rectification of Spot 5 satellite imagery for Marine Geographic Information Systems, Proc. in ARSA - Advanced Research in Scientific Areas, Virtual Conference, 2012, 1649-1653.

[8] A. Errico, F. Guastaferro, C. Parente and R. Santamaria, Applications on geometric correction of different resolution satellite images, Proc. of the IEEE GOLD Conference 2010, Livorno, Italy, 2010. http://ieee.uniparthenope.it/chapter/_private/proc10/29.pdf.

[9] I. Parcharidis, M. Foumelis, E. Papageorgiou, M. Segou and V. Sakkas, Orthorectification and assessment of quickbird imagery using d-gps measurements over paros urban area, Proc. of the International Society Photogrammetry and Remote Sensing 2005 Joint Conference, Tempe, AZ, 2005. http://www.isprs.org/proceedings/xxxvi/8-w27/parcharidis.pdf.

[10] M. Basile Giannini, P. Maglione, C. Parente and Santamaria R., Cartography and remote sensing for coastal erosion analysis, WIT Transactions on Ecology and the Environment Volume 149, 2011, Pages 65-76 2nd International Conference on Physical Coastal Processes, Management and Engineering, Coastal Processes 2011, Naples, Italy, 27 April 2011 through 29 April 2011. ISBN 9781-84564-534-2.

[11] M. M. Calandrelli and R. Calandrelli, Bio-parks as a means of environmental restoration and enhancement for the sustainable management of a degraded land, Proc. of FIST GEOITALIA 2013, Pisa, Italy, 2013. http://www.cnr.it/istituti/ProdottoDellaRicerca.html?cds=010\&id=262764. 